\title{
Impact of endobronchial allergen provocation on macrophage phenotype in asthmatics
}

\author{
Carla Winkler ${ }^{1,2}$, Lena Witte ${ }^{1,2}$, Natali Moraw ${ }^{2}$, Conny Faulenbach², Meike Müller ${ }^{2}$, Olaf Holz ${ }^{2,3}$, \\ Frank Schaumann ${ }^{2}$ and Jens M Hohlfeld ${ }^{1,2,3^{*}}$
}

\begin{abstract}
Background: The role of $\mathrm{M} 2$ polarized macrophages $(M \Phi)$ during the allergic airway inflammation has been discussed in various animal models. However, their presence and relevance during the chronic and acute phase of allergic airway inflammation in humans has not been fully elucidated so far. In the present study we phenotypically characterized macrophages with regard to M2 polarization in mice, a human in vitro and a human ex vivo model with primary lung cells after endobronchial provocation.

Results: Macrophages remained polarized beyond clearance of the acute allergic airway inflammation in mice. Alveolar macrophages of asthmatics revealed increased mRNA expression of CCL13, CCL17 and CLEC10A in response to allergen challenge as well as increased surface expression of CD86. Further, mRNA expression of CCL13, CCL17, and CLEC10A was increased in asthmatics at baseline compared to healthy subjects. The mRNA expression of CCL17 and CLEC10A correlated significantly with the degree of eosinophilia (each $\mathrm{P}<.01$ ). Furthermore, macrophages from asthmatics released significant amounts of CCL17 protein in vitro which was also found increased in BAL fluid after allergen provocation.
\end{abstract}

Conclusions: This study supports previous findings of $\mathrm{M} 2$ macrophage polarization in asthmatic subjects during the acute course of the allergic inflammation and provides evidence for their contribution to the Th2 inflammation.

Keywords: Asthma, M2 macrophages, Endobronchial allergen provocation, Segmental allergen challenge

\section{Background}

Pulmonary dendritic cells, activated Th2 effector cells, and their respective cytokine and chemokine networks in the sensitization and initiation phase of allergic airway inflammation have been explored intensively [1-3]. The question, whether the most abundant resident cell type in the alveolar space, the macrophage, plays a significant role in these processes has been neglected in this setting for years [4]. Increasing knowledge about macrophage polarization brought alveolar macrophages back into focus. In the context of allergic airway inflammation the contribution of the alternatively activated M2 phenotype with its specific functionality appears to be of special interest [5].

\footnotetext{
* Correspondence: jens.hohlfeld@item.fraunhofer.de

'Department of Respiratory Medicine, Hannover Medical School, Hannover, Germany

${ }^{2}$ Fraunhofer Institute for Toxicology and Experimental Medicine, Hannover, Germany

Full list of author information is available at the end of the article
}

M2 polarization encompasses at least two subtypes M2 and M2-like macrophages dependent on the cytokine milieu macrophages are subjected to. M2 macrophages differentiate in response to IL-4 and IL-13 whereas M2like macrophages acquire their phenotype in response to TGF-b, IL-10 or PGE and additional TLR activation [6]. M2-like macrophages release high amounts of IL-10 and are thus considered to be anti-inflammatory. However, M2 macrophages are functionally considered to promote clearance of parasite infections [7], they are involved in tumor progression [8], and they contribute to tissue remodeling [9]. Markers for M2 macrophages differ between mice and man, with Ym1, Fizz1, Arg specifically described to be up-regulated in mice [10], whereas expression of the mannose receptor CD206 was defined for M2 macrophages from both species [11,12]. In humans, several markers for M2 polarization have been described such as up-regulation of HLA-DR and increased expression of Th2 chemokines CCL17, CCL18, CCL22 and CCL24 [13]. Importantly, most data on macrophage polarization are

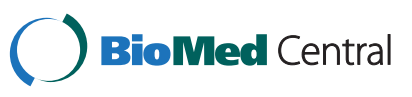


derived from animal studies. M2 markers between mice and man are not identical, and our understanding of the characteristics of M2 polarization in human asthma is still incomplete [14]. Recently, Staples and colleagues published an important paper in which they phenotypically characterized M2 polarization of alveolar macrophages in a group of non-asthmatic subjects and asthmatic patients [15]. Using the currently accepted panel of human M2 markers, they showed a partial M2 polarization of sputum and BAL macrophages in symptom-free asthmatics. Interestingly, the CCR4 ligand CCL17, a key chemokine for the recruitment of $\mathrm{CCR}^{+}$effector cells, was prominently induced, indicating that M2 macrophages might also facilitate the inflammatory immune response in humans.

With the current study we extended the phenotypic and functional characterization of alveolar macrophages in asthmatic patients, by paying special attention to the late phase of allergic airway inflammation. Therefore, we investigated macrophage polarization before and after endobronchial allergen challenge. As significant levels of IL-4 and IL-13 are predominantly present in the acute effector phase of the allergen response, we first assessed the kinetics of macrophage polarization in a murine asthma model beyond the acute phase of inflammation. To study M2 polarization, we further established a human in vitro model with monocyte-derived macrophages (MDM) of atopic donors. Subsequently, human alveolar macrophages isolated from non-asthmatic and mild asthmatic subjects undergoing an endobronchial allergen challenge were analyzed. Two doses of allergen were used in separate lobes of the subjects in order to investigate the impact of the severity of the inflammatory response on the extent of polarization. Our findings confirm and extend previous findings and provide data about the plasticity of macrophages in mild asthmatic subjects under stable non-inflamed conditions and during the late phase of the allergic airway inflammation.

\section{Results}

M2 polarization persists after resolution of the acute allergic airway inflammation in mice

To evaluate the time course of alternative activation of pulmonary macrophages a mouse model of acute allergic airway inflammation was used to study the expression of M2 marker genes in alveolar and interstitial lung macrophages. The mRNA expression of previously described murine M2 markers (Arg, Fizz1 and Ym1) and iNOS (M1 marker) was analyzed over a period of three weeks after the induction of acute inflammation in mice. The inflammation kinetic assessed by inflammatory cell influx and cytokine levels in BAL revealed elevated eosinophils $24 \mathrm{~h}$ and 1 week after allergen provocation $(\mathrm{P}<.001)$, whereas IL-4 and IL-13 levels in BAL were only increased during the peak of the acute inflammation at $24 \mathrm{~h}(\mathrm{P}<.001)$ (Figure 1, A). Messenger RNA expression of Arg, Fizz1, and $\mathrm{Ym} 1$ was markedly increased in alveolar and interstitial

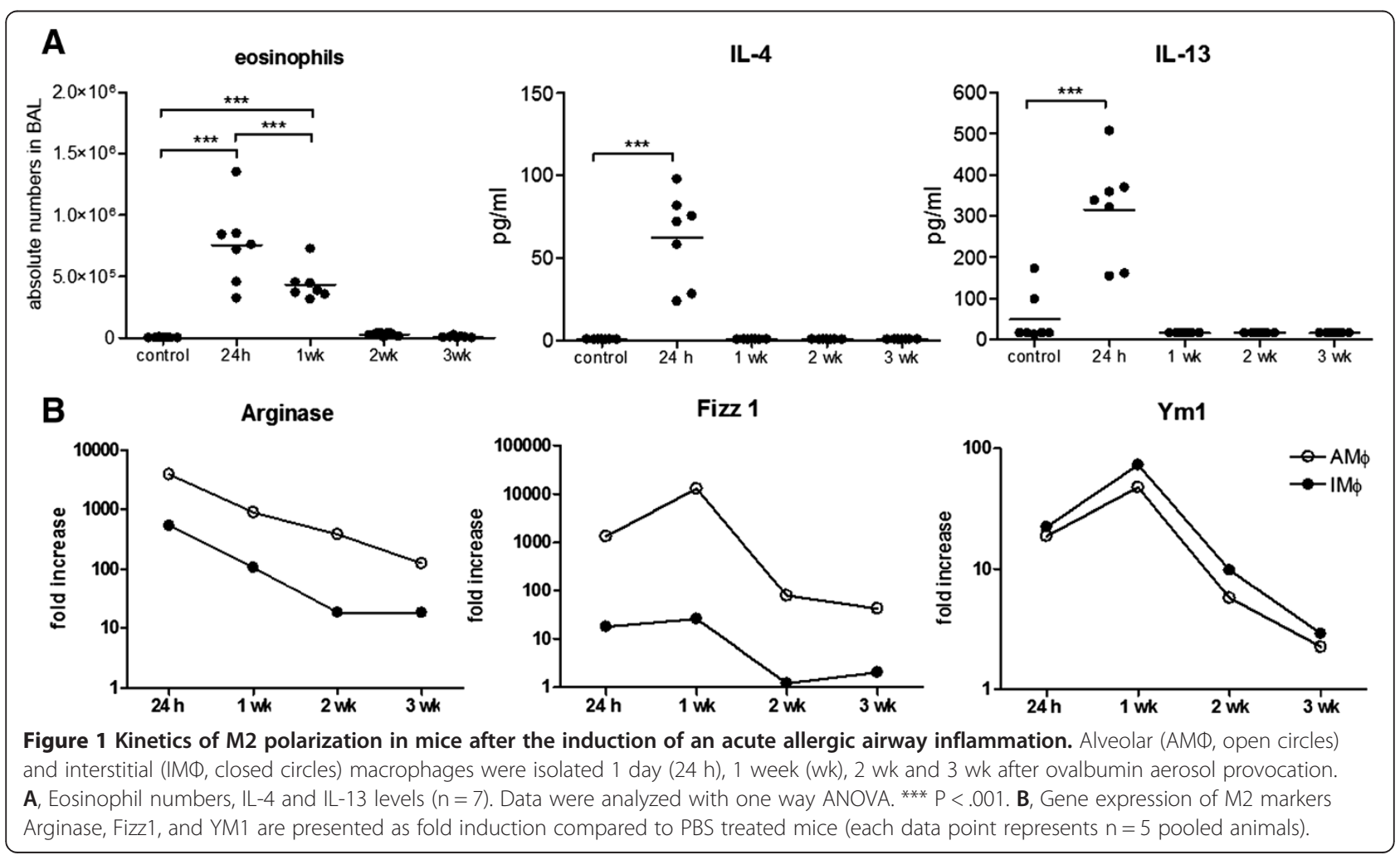


macrophages of ovalbumin sensitized animals compared to the control group (Figure 1, B) whereas iNOS mRNA expression was not altered (data not shown). The expression of M2 marker genes declined over time, but after three weeks AMФ still revealed a higher expression of these genes compared to the control group. Interestingly, the level of expression for the 3 genes in IM $\Phi$ and $A M \Phi$ constantly fell to $3.3 \pm 0.3 \%$ at 3 weeks compared to $24 \mathrm{~h}$.

\section{In vitro M2 polarization of human derived macrophages}

To characterize M2 markers in human cells in more detail, macrophages were generated from peripheral blood monocytes of atopic subjects and stimulated with IL-4 \pm allergen. Co-stimulatory surface markers like HLA-DR and CD86 were significantly up-regulated on the surface of macrophages in the presence of IL-4 $(\mathrm{P}<.01)$ compared to control macrophages (Figure 2, A). Protein expression of the mannose receptor (CD206) was not regulated by IL-4 (data not shown). Compared to control macrophages, the mRNA expression of M2 markers CCL13, CCL17, CCL18 (data not shown), CCL23 as well as CLEC10A were found to be significantly increased in the presence of IL-4 (all $\mathrm{P}<.01$ ) (Figure 2, B). Interestingly, the mRNA expression of CCL17 was further increased when allergen was present during stimulation with IL-4 $(\mathrm{P}<.01)$, whereas allergen exposure during culture had no effect on the mRNA expression of other M2 markers.

\section{Induction of autologous lymphocyte proliferation by human MDM}

As mouse M2 macrophages revealed an increase of costimulatory molecules and an enhanced endocytosis of soluble antigens [11], we investigated the potential of these macrophages to present antigen to autologous T-cells. Macrophages were generated from human peripheral monocytes isolated from asthmatic patients and stimulated with IL-4 and in addition with grass allergen extract prior to co-culture with autologous lymphocytes.

Native macrophages, not stimulated with IL-4, did not induce any T-cell proliferation in contrast to M2 (IL-4 stimulated) macrophages which induced low but significant induction of proliferation when primed with allergen $(\mathrm{P}<.01)$ (Figure 3, A). In comparison to professional antigen presenting dendritic cells (generated in the same model), M2 macrophages revealed a five-fold lower capacity to induce specific $\mathrm{T}$-cell proliferation (data not shown).

Analysis of cytokines in the supernatant after IL-4 stimulation revealed increased amounts of CCL17 compared to control MФ. Furthermore, macrophages induced Th2 cytokine release like IL-2, IL-10 and IL-13 by lymphocytes when stimulated with IL-4 and allergen (Figure 3, B). In

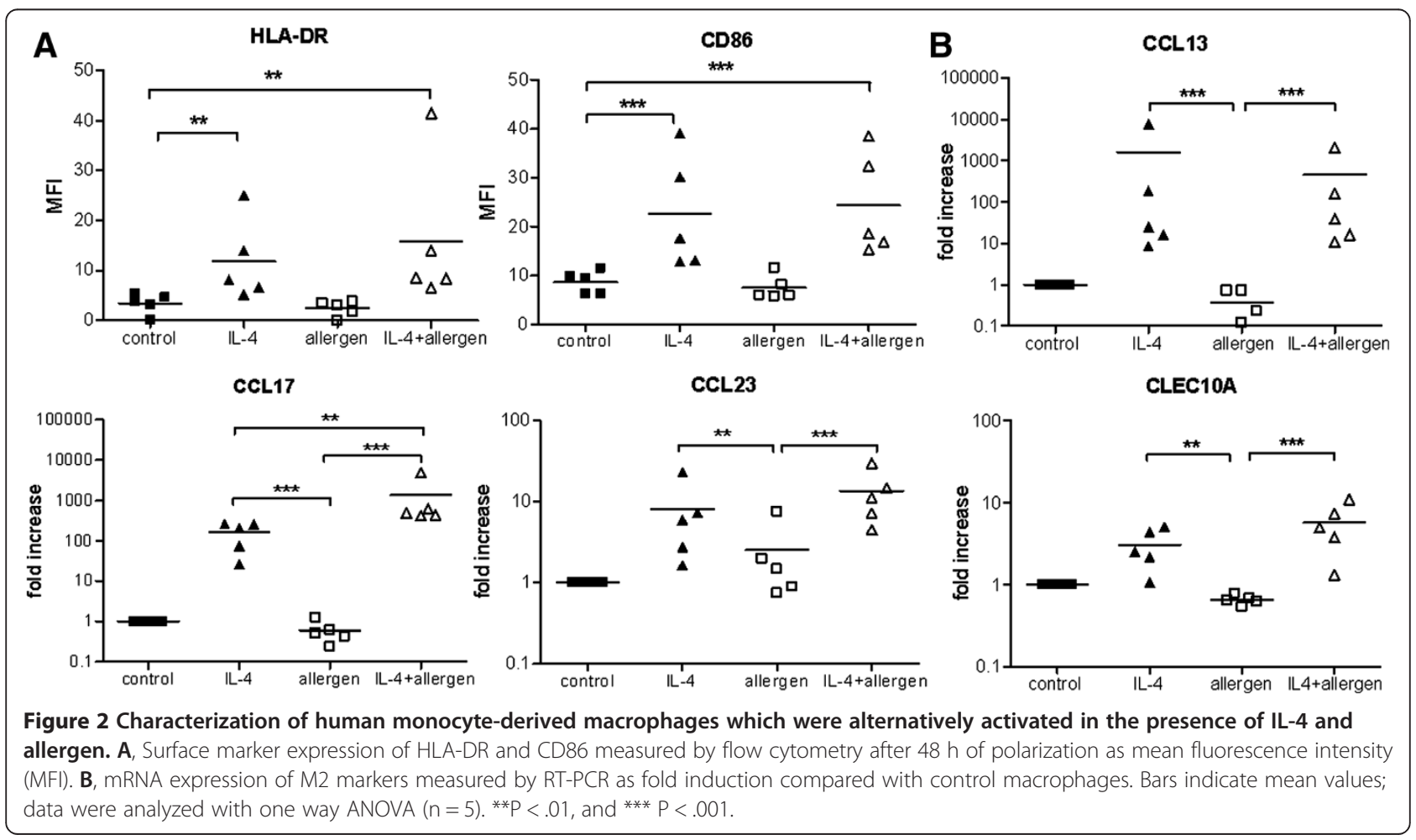




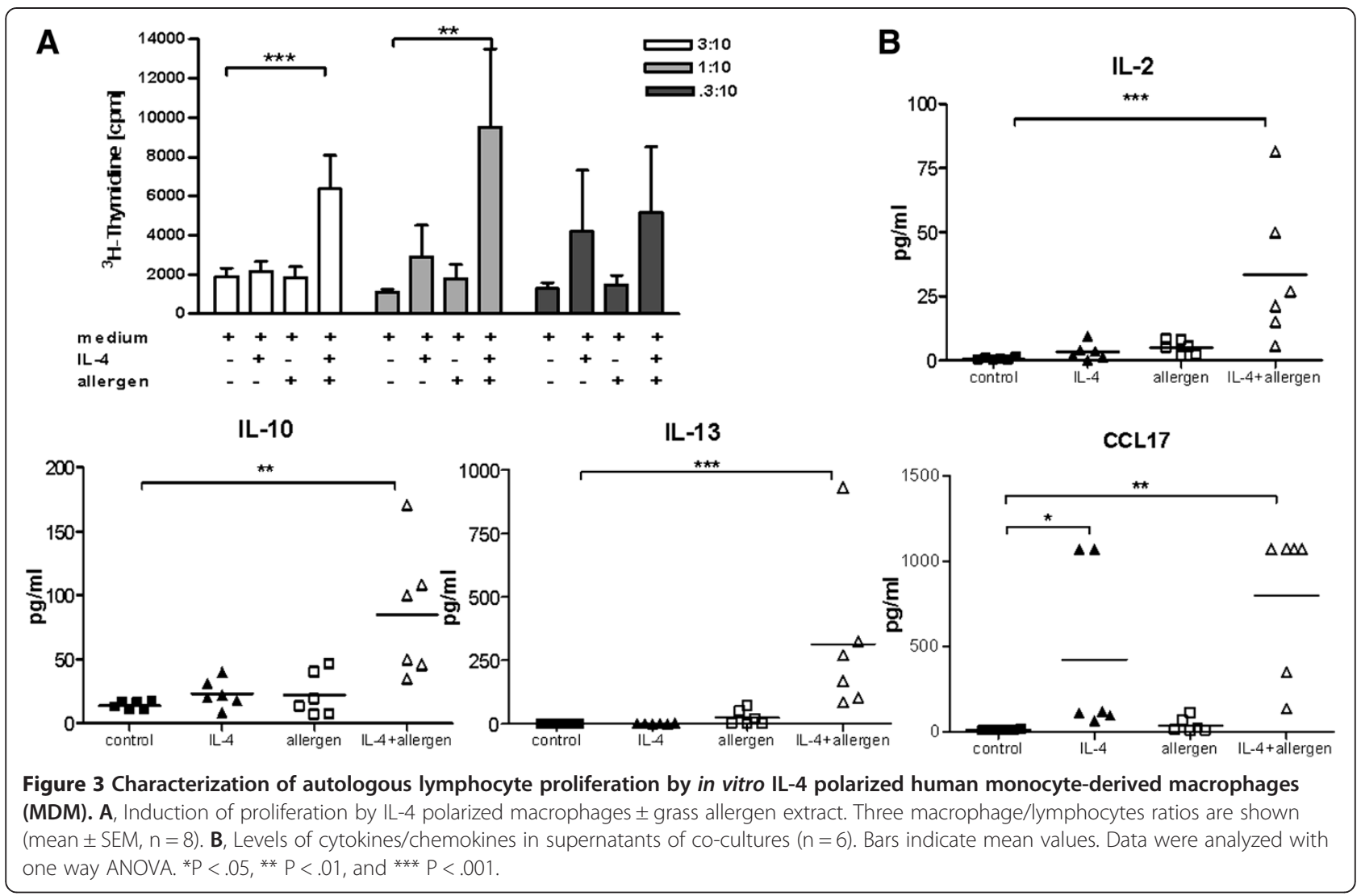

contrast, TNF- $\alpha$, CCL24, and CCL22 release were found unchanged compared to medium control macrophages (data not shown).

\section{M2 polarization of human $A M \Phi$ after endobronchial allergen challenge}

Next, we investigated the extent of macrophage polarization after endobronchial allergen challenge in healthy and asthmatic subjects (Table 1). The inflammatory response in the control and allergen challenged segments was assessed by cell differentiation and cytokine measurements

Table 1 Patient characteristics

\begin{tabular}{lcc}
\hline & Healthy & Asthmatic \\
\hline No. & 4 & 11 \\
Sex (male/female) & $4 / 0$ & $9 / 2$ \\
Age (y) & $45(40-50)$ & $43(37-50)$ \\
Atopy & no & yes \\
FEV1 (\% predicted) & $108.3(103.8-11.2)$ & $94(83.1-110.7)$ \\
FEV1/FVC ratio & $79.6(75.1-80.3)$ & $76.2(70.8-86.7)$ \\
Metacholine PC 20 & n.d. & $1.5(0.9-5.7)$ \\
Allergen (BU/ml) & 100 & $62.5(62.5-125)$ \\
lgE (U/ml) & $23(9.5-68)$ & $173(97-262)$ \\
\hline
\end{tabular}

Median and interquartile ranges (IQR) are given. of the recovered BAL fluid. The two segments that received the standard allergen dose were similar with respect to the influx of eosinophils (Table 2). A lower percentage of eosinophils was found in the segment that received $1 / 10$ of the standard allergen dose $(\mathrm{P}<.01)$. Compared to baseline, levels of IL-5 in BAL increased after allergen provocation $(\mathrm{P}<.001)$, however with no significant differences between the allergen doses (Additional file 1: Figure S1). For further analysis, cells and supernatants from the two standard allergen segments were pooled. On protein level, CCL17 and CCL22 were found to be increased due to endobronchial allergen challenge with differences between allergen doses (Additional file 1: Figure S1) $(\mathrm{P}<.01)$.

The protein expression of CD86 measured by flow cytometry was significantly higher in macrophages from asthmatic patients compared to healthy subjects and further up-regulated after standard allergen provocation in asthmatic patients $(\mathrm{P}<.05)$ (Figure $4, \mathrm{~A})$. The MFI value of surface HLA-DR was higher in asthmatic patients compared to non-asthmatic subjects but did not reach statistical significance. No differences were observed for the surface expression of CD206 (Figure 4, A).

Compared to isolated macrophages from the saline segment, the mRNA expression of CCL13, CCL17, and CLEC10A (normalized to individual baseline expression) was increased after application of the standard allergen 
Table 2 Bronchoalveolar lavage data

\begin{tabular}{|c|c|c|c|c|c|c|c|}
\hline Segment & Recovery (ml) & Total cells $\left(x 10^{6}\right)$ & Macrophages (\%) & Eosinophils (\%) & Neutrophils (\%) & Lymphocytes (\%) & Epithelial cells (\%) \\
\hline $\bar{B}(H)$ & 49 (35-58.8) & $2.1(1.5-3.6)$ & $91(88.3-92.9)$ & 0 & $1(0.6-1.8)$ & $7.4(4.5-9.8)$ & $0.8(0.5-1.8)$ \\
\hline $\mathbf{S}(H)$ & 73.5 (66.5-78) & $7.7(4.4-15.3)$ & $88.9(61.2-92)$ & $0.3(0-0.6)$ & $2.4(1.2-31)$ & $5(3.4-8.3)$ & $0.7(0.2-2.3)$ \\
\hline $\mathbf{A}_{1 / 10}(H)$ & $68.5(64-78)$ & $5.4(5.3-6.2)$ & 86.7 (76.1-93.4) & $0.5(0-1.6)$ & $6.5(1.6-12.5)$ & $6.6(2.5-10.3)$ & $0.1(0-2.8)$ \\
\hline A1 $(H)$ & $55.5(47-61)$ & $3.5(2.7-5.5)$ & 79.4 (73.7-86.3) & $0.2(0.4)$ & $7.8(3.3-11.3)$ & $7.8(3.3-10.4)$ & $0.6(0.3-1.1)$ \\
\hline $\mathbf{B}(A)$ & $52.0(44-60)$ & $4.7(1.2-5.7)$ & $91.3(81-93.8)$ & $0.3(.0 .5)$ & $2(0.3-2.3)$ & $5.8(3-12)$ & $1(0.8-2.5)$ \\
\hline $\mathbf{S}(A)$ & $55(51-69)$ & $5.6(2.6-9.5)$ & 88.3 (84.8-91) & $0.3(0-1.3)$ & $3.8(1.3-9.8)$ & $5(3.3-7.8)$ & $0.8(0.3-2)$ \\
\hline $\mathbf{A}_{1 / 10}(A)$ & $54(47-63)$ & $6(3.9-14.2)$ & $70.3(29-84.5)$ & $7.8(3-30.3)^{* * * \S}$ & $3.5(1.3-18.8)$ & $3.8(2-6.5)$ & $1(0.3-1.3)$ \\
\hline $\mathbf{A} \mathbf{1}(\mathrm{A})$ & $56(48-63)$ & $9.3(3.9-20.9)$ & $47.3(31.3-63.8)^{* * * \S \#}$ & $30.8(12.8-46)^{* * * \S \#}$ & $6.3(1.8-9.3)$ & $3.5(2.5-4.8)$ & $0(0-0.7)$ \\
\hline A2 (A) & $43(32-63)$ & $8.1(5-13.1)$ & $38\left(27.7-56.3^{* * * \S \#}\right.$ & $38.3(10.3-63.8)^{* * * \text { §\# }}$ & $6.5(2.3-18)^{* *}$ & $3.8(2.3-6)$ & $0.3(0-9)$ \\
\hline
\end{tabular}

$(H)$ Healthy subjects, and $(A)$ asthmatic patients who underwent bronchoalveolar lavage at baseline (B) and 24 hours after instillation with saline (S), standard allergen $(A)$, in two different segments ( $A 1$ and $A 2)$, and one-tenth of the standard allergen dose (A1/10). Median and interquartile ranges (IQR) are given. ${ }^{* * *}$ versus baseline $P<.001,{ }^{* *}$ versus baseline $P<.01$, $\S$ versus saline $P<.001$, \# versus $A_{1 / 10} P<.01$

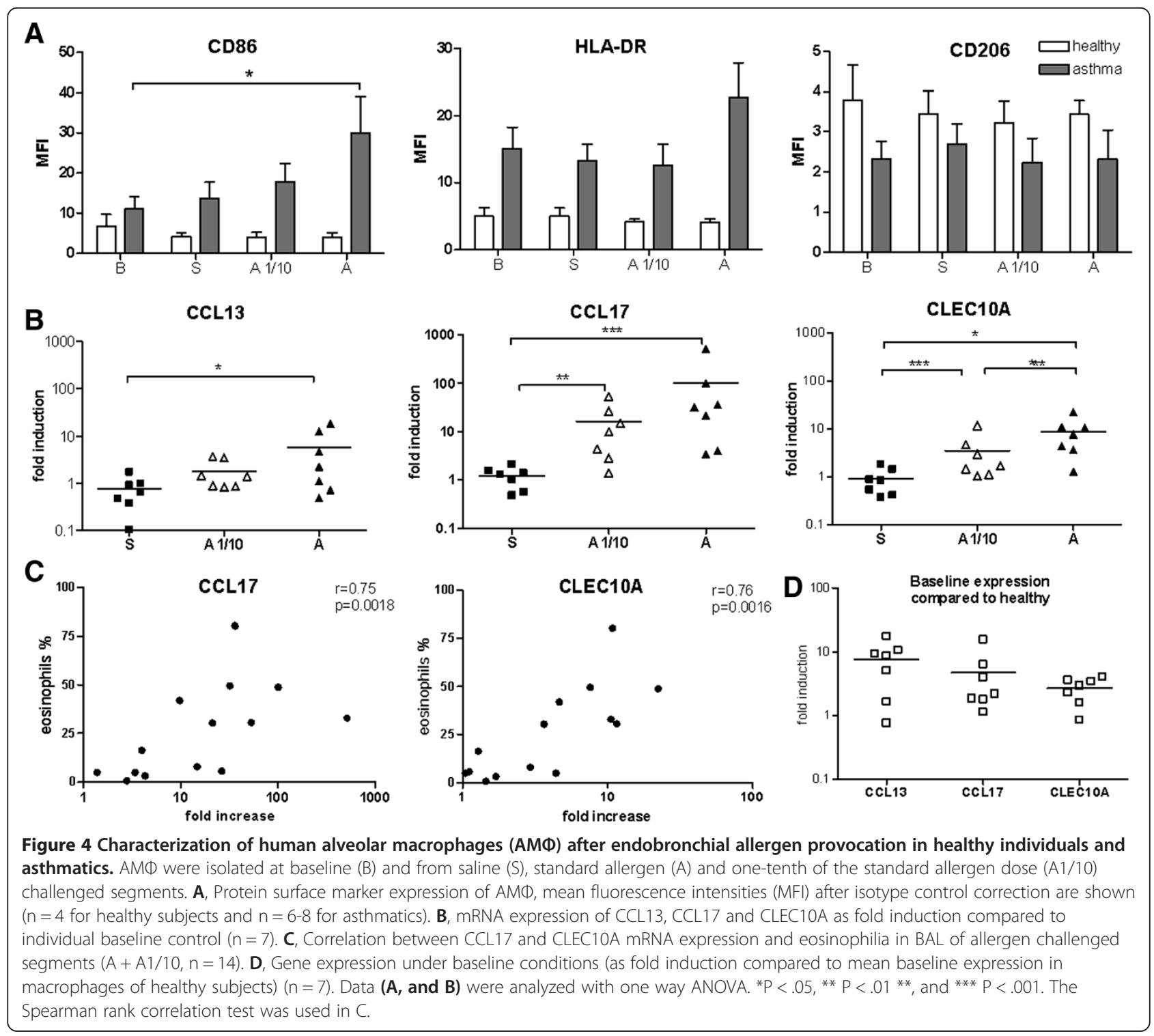


dose, while low dose allergen challenge increased CCL17 and CLEC10A but not CCL13 $(\mathrm{P}<.05)$ (Figure 4, B). In contrast, the mRNA expression of CD206, CCL18, CCL23, and the M1 marker CXCL10 were not changed by allergen provocation (Additional file 2: Figure S2). In healthy subjects no alteration of M2 marker mRNA expression was observed in isolated macrophages in none of the different segments (Additional file 3: Figure S3).

The mRNA expression of CCL17 and CLEC10A (Figure 4, C) in macrophages isolated from the standard allergen and low allergen segment correlated with the percentage of eosinophils in BAL fluid $(r=.76, \mathrm{P}=.002$ and $\mathrm{r}=.75, \mathrm{P}=.002$, respectively). As mRNA expression of M2 markers in healthy subjects was not altered due to allergen exposure, we normalized expression levels in macrophages from asthmatic subjects relative to mean baseline values of healthy subjects (= fold induction, Figure 4, D and Additional file 2: Figure S2). This analysis showed an increased baseline expression of CCL13, CCL17 and CLEC10A in macrophages from asthmatics patients compared to healthy subjects.

\section{Human $А M \Phi$ from endobronchial allergen challenged lung segments are functionally altered}

According to the in vitro model using human MDM and autologous T-cells from peripheral blood, we evaluated the induction of antigen-specific T-cell proliferation of human $A M \Phi$ which were primed with allergen in vivo. Alveolar macrophages were isolated from BAL fluid by adherence and co-cultured with autologous T-cells from peripheral blood.

Mean values of T-cell proliferation were higher with macrophages isolated from the low dose and standard allergen dose challenged segments, respectively compared to the saline segment $(\mathrm{P}<.01$, Figure $5, \mathrm{~A})$. However, the overall magnitude of proliferation was about 10-fold lower when compared to the proliferation induced by pulmonary myeloid dendritic cells of asthmatic patients in a previous study. In this study dendritic cells were isolated from BAL after endobronchial allergen challenge by flow cytometry based cell sorting and cocultured likewise with autologous lymphocytes [16]. Cytokine and chemokine analysis of co-culture supernatants of either AM $\Phi$ or AM $\Phi+\mathrm{T}$-cells showed that AMФ isolated from asthmatics after endobronchial allergen challenge released increased amounts of CCL17 and CCL22 compared to AMФ isolated from the saline challenged segment $(\mathrm{P}<.01$, Figure $5, \mathrm{~B})$. In addition increased levels of CCL17 and CLL22 were also found in BAL fluid from asthmatic patients after endobronchial allergen challenge with both allergen doses (Additional file 1: Figure S1).

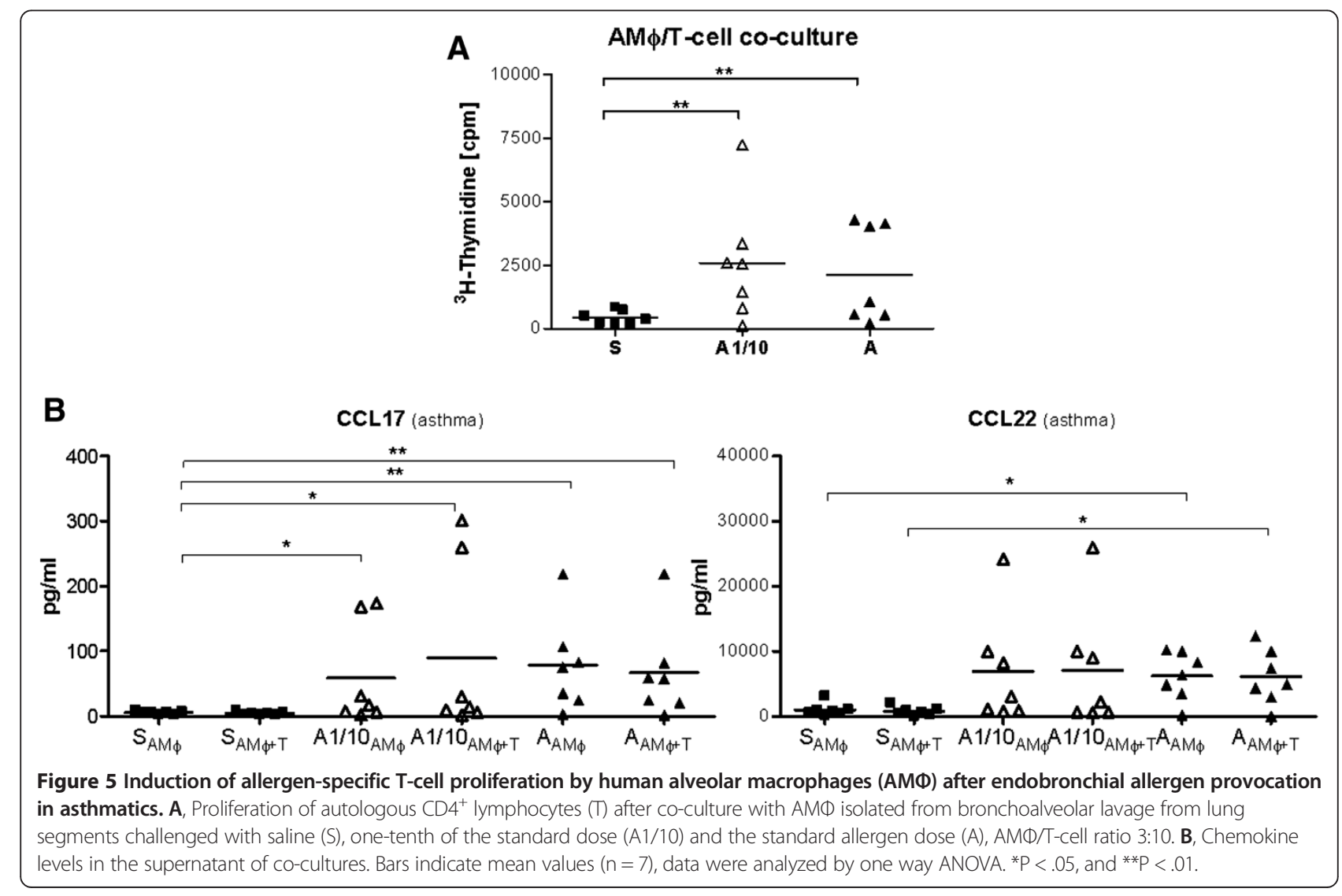


In contrast to the human MDM co-culture model, no induction of Th2 cytokines by $\mathrm{CD} 4^{+} \mathrm{T}$-cells was observed. Alveolar macrophages isolated from healthy subjects did not induce any proliferation nor did they release CLL17 or CLL22 (data not shown).

\section{Discussion}

This study provides evidence for an augmented expression of CCL13, CCL17, and CLEC10A in AMФ from patients with mild asthma during episodes of acute allergic airway inflammation. The expression of macrophage CCL17 and CLEC10A was related to the degree of eosinophilic inflammation. As increased amounts of CCL17 have been shown to attract CCR4 ${ }^{+}$effector cells like eosinophils or specific Th2 lymphocyte subsets $[17,18]$, it is tempting to speculate that macrophages play an important role in modulating the degree of allergic inflammation. Our data is in line with and confirms recent results of Staples and co-workers, who showed that human AMФ from asthmatic patients display a partial M2 polarization already under non-inflamed conditions with increased mRNA expression of CCL17, CLEC10A and protein release of CLL17 and CCL22 [15].

It has been demonstrated in mouse models that macrophages undergo M2 polarization during the acute phase of allergic airway inflammation. However, the time course of polarization markers after resolution of the acute inflammation has not been investigated. Our data demonstrate that the up-regulated expression of established murine M2 polarization markers (Ym1, Fizz1, and Arg) outlive the inflammatory response. The decline of polarization markers over time might be due to replacement by new monocytes entering the alveolar space after resolution of the cellular inflammation, which is also supported by the concordant and continuous decline of all 3 investigated M2 related genes. An impaired phagocytosis of E. coli by murine M2 macrophages supports the hypothesis that clearance mechanisms might be altered, making the airways more susceptible for bacterial or viral infection during this resolution period [19]. Therefore, polarized macrophages seem to be capable to play a role in sustaining an inflammatory condition after acute allergen exposure.

We found several markers of M2 polarization to be induced in response to IL-4 in human MDM such as CCL17 and CLEC10A. These polarized macrophages induced allergen-specific T-cell proliferation and Th2 cytokine secretion. Importantly, IL-4 polarized human MDM do not fully reflect the AMФ phenotype in asthmatics, as the cytokine milieu in vivo is not restricted to solely M2 stimuli.

It was previously shown that IL-4 stimulation of murine macrophages in vitro leads to increased CCL17 release $[18,20]$. We could extend these findings for human AMФ derived from allergen challenged segments as these cells express increased amounts of CCL17 on mRNA and protein level after allergen challenge. However, it remains to be elucidated to which extent macrophages account for the increased CCL17 levels in BAL of asthmatic patients since dendritic cells and epithelial cells have also been identified as prominent sources [21-24]. We did not observe CCL17 release by native T-cells of asthmatic patients in our co-cultures [25]. In opposite to findings of Staples, we found CCL17 mRNA already increased at baseline in macrophages from mild asthmatic patients compared to healthy subjects and additionally identified CCL13 to be up-regulated. CCL13 is a potent chemokine which attracts $\mathrm{CCR}^{+}$cells like eosinophils, Th2-lymphocytes, basophils and correlates with asthma exacerbation [26,27]. CCL13 protein has been shown to be increased in BAL of asthmatic patients compared to healthy controls [28]. Our mRNA results in $\mathrm{AM} \Phi$ show that polarized macrophages represent an additional source of this protein beside epithelial cells in response to allergen provocation in the airways.

The macrophage galactose-type C-type lectin (MGL) CLEC10A which we and others found up-regulated on alveolar macrophages from asthmatic patients [15] recognizes carbohydrate structures with terminal galactose or $\mathrm{N}$-acetylgalactosamine residues, which are present on naturally occurring allergens [12,29]. Additionally, the mannose receptor (CD206) [30] and IgG receptor (CD32) [31] are described to be increased on macrophages from asthmatic patients. Whether this up-regulation is capable to alter phagocytosis of M2 macrophages remains to be elucidated. Interestingly, phagocytosis of bacteria is impaired in patients with severe asthma [32,33] and IgG-opsonized yeast are less effectively cleared by macrophages from asthmatic patients [34]. Impaired phagocytosis of bacteria was also reported from various in vitro models of M2 polarization, also supporting the hypothesis that pulmonary clearance of inhaled pathogens might be hampered [35]. In our study, CD206 was not differentially expressed on macrophages from asthmatic patients compared to healthy subjects and not regulated in response to allergen exposure.

In asthmatic patients chitinases (chitotriosidase, CHIT1) and chitinase-like proteins (YKL-40) in serum and BAL correlate with the severity of the disease, the degree of airway remodeling, and the frequency of asthma exacerbations [36-38]. These molecules are released from activated monocytes and macrophages and are suggested to be linked with remodeling processes $[39,40]$. CCL18, a macrophage-derived chemokine has been described to attract T-lymphocytes and to promote collagen production by human fibroblasts $[41,42]$. Interestingly, we did not observe CCL18 up-regulation in alveolar macrophages $24 \mathrm{~h}$ after segmental allergen challenge, while we 
found CCL18 increased in MDM in vitro at $48 \mathrm{~h}$ after IL-4 stimulation. This is in line with a recent in vitro study investigating the kinetics of CCL18 induction showing maximum release at $72 \mathrm{~h}$ but no significant change at $24 \mathrm{~h}$ after stimulation with allergen [41]. In line with older reports, we found an increased expression of HLA-DR and other co-stimulatory surface markers on M2 macrophages [31,43]. Although the results from our in vitro allergy model show that M2 macrophages induce T-cell proliferation and the release of Th2 cytokines, we were not able to confirm the magnitude of proliferation and cytokine release in similar experiments using AMФ. Consequently, this questions their relevance for allergen presentation. As a limitation, we did not investigate whether macrophages from asthmatic patients exhibit a suppressive function on DC-induced T-lymphocyte proliferation as has been reported before [44].

There is increasing evidence that the different models available to study the concept of macrophage polarization are providing controversial results. Murine models of allergic asthma revealed that the course of the allergic airway inflammation was not influenced by the presence or absence of IL-4 receptor- $\alpha$ bearing macrophages which become polarized during the allergic inflammation [45]. In contrast, the transfer of IL-4 receptor-bearing macrophages aggravated the eosinophilic inflammation in IL-4 receptor-deficient mice [46]. However, in an animal model of acute exacerbation M2 macrophages triggered Th2 cytokines in $\mathrm{CD}_{4}^{+} \mathrm{T}$-lymphocytes through the interaction with CD80/CD86, which was not seen in a model of mild chronic asthma [47]. A rhinovirusinduced exacerbation study identified M2 macrophages after allergen challenge which subsequently released more Th2 cytokines and CCL11 after additional rhinovirus infection. On the other side, depletion of macrophages before allergen/rhinovirus challenge lead to reduced eosinophilia, CCL11 and IL-13 levels [48]. Thus, functional consequences of macrophage polarization might become more apparent during asthma exacerbation phases.

\section{Conclusions}

The main focus of our study was the role of macrophage polarization in asthmatic patients. Taken together, we were able to show a close relationship between the degree of eosinophilic inflammation and M2 polarization, which is characterized by an increased expression of CCL13, CCL17 and CLEC10A. Together with the data from the animal and in-vitro models these data indicate that M2 macrophages might contribute to the acute inflammation by their Th2 cytokine and chemokine release. Future studies need to refine functional implications of M2 polarized macrophages in particular with pathogen-induced exacerbations and with different asthma phenotypes.

\section{Methods}

\section{Kinetics of M2 marker expression in a mouse model of} acute asthma

Female BALB/c mice of 6-8 weeks of age were sensitized according to the standard acute ovalbumin (ova)-model as described before [49]. Mice were killed 24 h, 1 week, 2 weeks and 3 weeks after the last ova-aerosol challenge (see methods section in the supplement). Alveolar macrophages $(\mathrm{AM} \Phi)$ were isolated from BAL by adherence to plastic for $1 \mathrm{~h}$ at $37^{\circ} \mathrm{C}$ and $5 \% \mathrm{CO}_{2}$. Interstitial macrophages (IM $\Phi)$ were isolated from lung digests by antiCD11b magnetic bead separation (Miltenyi Biotech, Bergisch Gladbach, Germany) and subsequent plastic adherence to remove contaminating cells. Real time PCR of M2 marker gene expression and cytokine measurement in BAL was performed as described below.

\section{Clinical study design and study population}

Peripheral blood derived mononuclear cells (PBMC) and autologous lymphocytes were obtained from eight atopic subjects who were allergic to grass. For isolation of AMФ, eleven patients with mild intermittent asthma and four healthy controls underwent endobronchial allergen provocation with grass allergen extract (SQ225, Alk-Albello Arzneimittel GmbH, Hamburg, Germany) as described in detail before (see the methods section in the supplement) $[50,51]$. For isolation of $\mathrm{CD}^{+}$lymphocytes peripheral blood was taken one day before endobronchial allergen challenge. The clinical study was performed in compliance with the Declaration of Helsinki. The Ethics committee of Hannover Medical School approved the study (ref. \#5670). All study subjects gave written consent after being fully informed about the purpose of study and the potential risks that were associated with the study procedures.

\section{Characterization of in vitro polarized human monocyte derived macrophages}

Isolation of monocytes and lymphocytes from peripheral blood of atopic individuals was performed as described before [52]. Briefly, PBMC were isolated from whole blood by density gradient centrifugation using FicollPaque PLUS (GE Healthcare Europe, Freiburg, Germany). Monocytes were isolated with anti-CD14 antibodies (Miltenyi Biotech, Bergisch Gladbach, Germany) by magnetic cell separation of PBMC and cultured for 6 days in RPMI 1640 + Glutamax (supplemented with 7\% of autologous serum and $800 \mathrm{U} / \mathrm{ml}$ GM-CSF). GM-CSF was chosen for differentiation as it leads to macrophages which resemble more closely the alveolar phenotype [53]. Cells negative for CD14 were collected as lymphocytes and kept frozen until co-culture at $-80^{\circ} \mathrm{C}$. After differentiation to macrophages cells were alternatively activated with $10 \mathrm{ng} / \mathrm{ml} \mathrm{IL}-4$ for $24 \mathrm{~h}$ and afterwards stimulated with $2000 \mathrm{BU} / \mathrm{ml}$ grass allergen extract (SQ225, Alk-Albello 
Arzneimittel GmbH, Hamburg, Germany) for 48 h. Cells were harvested and splitted for either analysis of surface markers or M2 marker gene expression or further co-cultured with autologous lymphocytes.

\section{Isolation of human alveolar macrophages after endobronchial allergen challenge}

Cells from BAL were re-suspended in culture medium with $7 \%$ autologous serum. Macrophages were isolated by plastic adherence for $1 \mathrm{~h}$ at $37^{\circ} \mathrm{C}$ and $5 \% \mathrm{CO}_{2}$. Adherent cells were washed 3 times with PBS and either transferred to RLT-buffer (Qiagen, Hilden, Germany) for RT-PCR analysis or co-cultured with autologous lymphocytes.

\section{Co-culture of human macrophages and autologous CD4 ${ }^{+}$ lymphocytes}

Both, monocyte-derived macrophages and AMФ were co-cultured with autologous lymphocytes in three or two ratios, respectively $(0.3: 10,1: 10$ and $3: 10)$. In detail, 0.3-3 $\times 10^{4}$ macrophages were cultured per well with $1 \times$ $10^{5}$ lymphocytes in triplicates. Proliferation was assessed by ${ }^{3} \mathrm{H}$-thymidine incorporation after 5 days of culture as described before [19]. For co-culture of AMФ autologous $\mathrm{CD}^{+}$lymphocytes were isolated by negative depletion using Dynabeads (Invitrogen, Darmstadt, Germany) from peripheral blood. An AMФ/T-lymphocyte ratio of 1:10 and 3:10 was analyzed. For cytokine measurements, supernatants from $\mathrm{AM} \Phi$ that were cultured for 5 days in the presence or absence of grass allergen extract $(2000 \mathrm{BU} / \mathrm{ml})$ were analyzed.

\section{Analysis of M2 markers by RT-PCR}

RNA was extracted either from MDM or from $\mathrm{AM} \Phi$ after plastic adherence using RNeasy Mini Kit (Qiagen, Hilden, Germany) according to the manufactures instructions. RNA transcription was performed with an Omniskript Reverse Transcription Kit (Roche, Basel, Switzerland). Real time PCR was performed with LightCycler ${ }^{\circ}$ FastStart DNA Master ${ }^{\text {Plus }}$ Sybr Green 1 (Roche, Basel, Switzerland) (see the methods section in the supplement). The expression of marker genes was normalized to a house keeping gene ( $\beta$-actin for mouse and GAPDH for human samples) and quantified according to the $\Delta \Delta \mathrm{Ct}$-method [54].

\section{Analysis of cytokines from supernatants of human MDM or $\mathrm{AM} \Phi$, and BAL fluid}

Release of cytokines to supernatants of in vitro cell cultures was performed by Multiplex MAP cytokines/ chemokine panels (Merck Millipore, Billerica, USA). Measurement of cytokines and chemokines in BAL was performed using a Th1/Th2 10-plex from MSD (Meso Scale Discovery, Rockville, USA).

\section{Statistics}

Statistical analyses were performed using one way Anova with Newman-Keuls post hoc testing. (GraphPad Prism Version 4; GraphPad Software, San Diego, California). Data were log-transformed if not normally distributed. Results were considered to be significant at a $\mathrm{P}$ value of $<0.05$.

\section{Additional files}

\begin{abstract}
Additional file 1: Figure S1. Cytokines and chemokines in bronchoalveolar lavage fluid (BAL) after segmental allergen provocation in asthmatic patients. Patients underwent BAL at baseline (B) and 24 hours after instillation with saline (S), one-tenth of the standard dose $(A 1 / 10)$ and standard allergen (A) in two different segments (A1 + A2). Levels of IL-5, CCL17, and CCL22 are shown. BAL from both standard allergen segments $(A=A 1+A 2)$ was pooled for CCL17 and CCL22 measurement. Bars indicate mean values $(n=11)$; data were analyzed by one way ANOVA. ${ }^{*} \mathrm{P}<.05,{ }^{*} \mathrm{P}<.01$ and ${ }^{* *} \mathrm{P}<.001$.
\end{abstract}

Additional file 2: Figure S2. Gene expression of M2 marker genes in alveolar macrophages from asthmatic patients. Asthmatic patients underwent bronchoalveolar lavage at baseline (B) and $24 \mathrm{~h}$ after provocation with saline $(S)$, standard allergen $(A)$ and one-tenth of the standard allergen dose (A1/10). RNA expression is shown as fold induction compared to the mean baseline expression in healthy patients $(n=7)$.

Additional file 3: Figure S3. Gene expression of M2 marker genes in alveolar macrophages from healthy patients. Healthy subjects underwent bronchoalveolar lavage at baseline (B) and $24 \mathrm{~h}$ after provocation with saline $(S)$, standard allergen $(A)$ and one-tenth of the standard allergen dose $(A 1 / 10)$. RNA expression is shown as fold induction compared to the individual baseline expression in healthy patients $(n=4)$.

\section{Abbreviations}

AF647: Alexa Fluor 647; AMФ: alveolar macrophages; APC: Allophycocyanin; Arg1: Arginase 1; BAL: Bronchoalveolar lavage; CLEC10A: Macrophage galactose C-type lectin (CD301); cpm: Counts per minute; CXCL10: Interferon gamma induced protein (IP10); DC: Dendritic cells; FACS: Fluorescenceactivated cell sorting; FIZZ1: Found in inflammatory zone; M1: Classically activated (macrophages); IMФ: Interstitial macrophages; i.p.: Intraperitoneal; M2: Alternatively activated (macrophages); MDM: Monocyte-derived macrophages; ova: Ovalbumin; PE: Phycoerythrin; PBMC: Peripheral blood derived mononuclear cells; PE-Cy7: Phycoerythrin-cyanine 7; Ym1: T-lymphocyte-derived eosinophil chemotactic factor (ECF-L).

\section{Competing interests}

The authors declare that they have no competing interests.

\section{Authors' contributions}

CW has made substantial contributions to conception and design, acquisition and interpretation of data and drafting the manuscript. LW carried out the sample preparation and analysis (RT-PCR, FACS and cytokines) of human pulmonary cells. NM carried out the mouse model and the MDM in vitro data. CF and FS performed the bronchoscopy study. MM contributed to the study conception and design. $\mathrm{OH}$ performed the statistical analysis and contributed to draft the manuscript. $\mathrm{JMH}$ has made substantial contributions to the study design, drafting the manuscript and funding acquisition. All authors read and approved the final manuscript.

\section{Acknowledgements}

This work was supported by the Deutsche Forschungsgemeinschaft (SFB587/B8) and BMBF-DZL, both to JMH. The authors thank the staff of the Department of Clinical Airway Research for their help with conducting the clinical study.

\section{Author details}

${ }^{1}$ Department of Respiratory Medicine, Hannover Medical School, Hannover, Germany. ${ }^{2}$ Fraunhofer Institute for Toxicology and Experimental Medicine, Hannover, Germany. ${ }^{3}$ Biomedical Research in Endstage and Obstructive Lung Disease Hannover (BREATH), Member of the German Center for Lung Research, Hannover, Germany. 
Received: 14 August 2013 Accepted: 21 February 2014

Published: 10 March 2014

\section{Reference}

1. Kazani S, Israel E: Update in asthma 2011. Am J Respir Crit Care Med 2012, 186:35-40.

2. Kool M, Hammad H, Lambrecht BN: Cellular networks controlling Th2 polarization in allergy and immunity. F1000 Biol Rep 2012, 4:6.

3. Willart M, Hammad H: Lung dendritic cell-epithelial cell crosstalk in Th2 responses to allergens. Curr Opin Immunol 2011, 23:772-777.

4. Peters-Golden M: The alveolar macrophage: the forgotten cell in asthma Am J Respir Cell Mol Biol 2004, 31:3-7.

5. Yang M, Kumar RK, Hansbro PM, Foster PS: Emerging roles of pulmonary macrophages in driving the development of severe asthma. J Leukoc Biol 2012, 91:557-569.

6. Boorsma CE, Draijer C, Melgert BN: Macrophage Heterogenity in Respiratory Diseases. Mediators Inflamm 2013, 769214:19 pages.

7. Noel W, Raes G, Hassanzadeh GG, De BP, Beschin A: Alternatively activated macrophages during parasite infections. Trends Parasitol 2004, 20:126-133.

8. Biswas SK, Mantovani A: Macrophage plasticity and interaction with lymphocyte subsets: cancer as a paradigm. Nat Immunol 2010, 11:889-896.

9. Mantovani A, Biswas SK, Galdiero MR, Sica A, Locati M: Macrophage plasticity and polarization in tissue repair and remodelling. J Pathol 2013, 229:176-185.

10. Raes G, De BP, Noel W, Beschin A, Brombacher F, Hassanzadeh GG: Differential expression of FIZZ1 and Ym1 in alternatively versus classically activated macrophages. J Leukoc Biol 2002, 71:597-602.

11. Stein M, Keshav S, Harris N, Gordon S: Interleukin 4 potently enhances murine macrophage mannose receptor activity: a marker of alternative immunologic macrophage activation. J Exp Med 1992, 176:287-292.

12. Melgert BN, Ten Hacken NH, Rutgers B, Timens W, Postma DS, Hylkema MN: More alternative activation of macrophages in lungs of asthmatic patients. J Allergy Clin Immunol 2011, 127:831-833.

13. Mantovani A, Sica A, Sozzani S, Allavena P, Vecchi A, Locati M The chemokine system in diverse forms of macrophage activation and polarization. Trends Immunol 2004, 25:677-686.

14. Martinez FO, Helming L, Milde R, Varin A, Melgert BN, Draijer C, Thomas B, Fabbri M, Crawshaw A, Ho LP, Ten Hacken NH, Cobos Jiménez V, Kootrat NA, Hamann J, Greaves DR, Locatti M, Mantovani A, Gordon S: Genetic programs expressed in resting and IL-4 alternatively activated mouse and human macrophages: similarities and differences. Blood 2013, 121:e57-e69.

15. Staples KJ, Hinks TS, Ward JA, Gunn V, Smith C, Djukanovic R: Phenotypic characterization of lung macrophages in asthmatic patients: Overexpression of CCL17. J Allergy Clin Immunol 2012, 130:1404-1412.

16. Schaumann F, Muller M, Braun A, Luettig B, Peden DB, Hohlfeld JM, Krug N: Endotoxin augments myeloid dendritic cell influx into the airways in patients with allergic asthma. Am J Respir Crit Care Med 2008, 177:1307-1313.

17. Vijayanand P, Durkin K, Hartmann G, Morjaria J, Seumois G, Staples KJ, Hall D, Bessant C, Bartholomew M, Howarth PH, Friedman PS, Djukanović R: Chemokine receptor 4 plays a key role in T cell recruitment into the airways of asthmatic patients. J Immunol 2010, 184:4568-4574.

18. Pilette C, Francis JN, Till SJ, Durham SR: CCR4 ligands are up-regulated in the airways of atopic asthmatics after segmental allergen challenge. Eur Respir J 2004, 23:876-884

19. Krysko O, Holtappels G, Zhang N, Kubica M, Deswarte K, Derycke L, Claeys S, Hammad H, Brusselle GG, Vandenabeele P, Krysko DV, Bachert C: Alternatively activated macrophages and impaired phagocytosis of S. aureus in chronic rhinosinusitis. Allergy 2011, 66:396-403.

20. Liddiard K, Welch JS, Lozach J, Heinz S, Glass CK, Greaves DR: Interleukin-4 induction of the CC chemokine TARC (CCL17) in murine macrophages is mediated by multiple STAT6 sites in the TARC gene promoter. BMC Mol Biol 2006, 7:45

21. Perros F, Hoogsteden HC, Coyle AJ, Lambrecht BN, Hammad H: Blockade of CCR4 in a humanized model of asthma reveals a critical role for DC-derived CCL17 and CCL22 in attracting Th2 cells and inducing airway inflammation. Allergy 2009, 64:995-1002.

22. Heijink IH, Marcel KP, van Oosterhout AJ, Postma DS, Kauffman HF, Vellenga E: Der $p, I L-4$, and TGF-beta cooperatively induce EGFR-dependent TARC expression in airway epithelium. Am J Respir Cell Mol Biol 2007, 36:351-359.
23. Berin MC, Eckmann L, Broide DH, Kagnoff MF: Regulated production of the T helper 2-type T-cell chemoattractant TARC by human bronchial epithelial cells in vitro and in human lung xenografts. Am J Respir Cell Mol Biol 2001, 24:382-389.

24. Ying S, O'Connor B, Ratoff J, Meng Q, Mallett K, Cousins D, Robinson D, Zhang G, Zhao J, Lee TH, Corrigan C: Thymic stromal lymphopoietin expression is increased in asthmatic airways and correlates with expression of Th2-attracting chemokines and disease severity. J Immunol 2005, 174:8183-8190.

25. Hirata H, Arima M, Cheng G, Honda K, Fukushima F, Yoshida N, Eda F, Fukuda T: Production of TARC and MDC by naive T cells in asthmatic patients. J Clin Immunol 2003, 23:34-45.

26. Kalayci O, Sonna LA, Woodruff PG, Camargo CA Jr, Luster AD, Lilly CM: Monocyte chemotactic protein-4 (MCP-4; CCL-13): a biomarker of asthma. J Asthma 2004, 41:27-33.

27. Romagnani S: Cytokines and chemoattractants in allergic inflammation. Mol Immunol 2002, 38:881-885.

28. Lamkhioued B, Garcia-Zepeda EA, Abi-Younes S, Nakamura H, Jedrzkiewicz S, Wagner L, Renzi PM, Allakhverdi Z, Lilly C, Hamid Q, Luster AD: Monocyte chemoattractant protein (MCP)-4 expression in the airways of patients with asthma. Induction in epithelial cells and mononuclear cells by proinflammatory cytokines. Am J Respir Crit Care Med 2000, 162:723-732.

29. Sano Y, Usami K, Izawa R, Denda-Nagai K, Higashi N, Kimura T, Suzuki N, Irimura T: Properties of blocking and non-blocking monoclonal antibodies specific for human macrophage galactose-type C-type lectin (MGL/ClecSF10A/CD301). J Biochem 2007, 141:127-136.

30. Wolden B, Smesta PB, Wold JK, Grimmer O: Characterization of the carbohydrate moiety in a purified allergen preparation from the mite Dermatophagoides farinae and its importance for allergenic activity as tested by rast-inhibition method. Int Arch Allergy Appl Immunol 1982, 68:144-151

31. Viksman MY, Bochner BS, Peebles RS, Schleimer RP, Liu MC: Expression of activation markers on alveolar macrophages in allergic asthmatics after endobronchial or whole-lung allergen challenge. Clin Immunol 2002, 104:77-85.

32. Fitzpatrick AM, Holguin F, Teague WG, Brown LA: Alveolar macrophage phagocytosis is impaired in children with poorly controlled asthma. J Allergy Clin Immunol 2008, 121:1372-1378.

33. Huynh ML, Malcolm KC, Kotaru C, Tilstra JA, Westcott JY, Fadok VA, Wenzel SE: Defective apoptotic cell phagocytosis attenuates prostaglandin E2 and 15-hydroxyeicosatetraenoic acid in severe asthma alveolar macrophages. Am J Respir Crit Care Med 2005, 172:972-979.

34. Alexis NE, Soukup J, Nierkens S, Becker S: Association between airway hyperreactivity and bronchial macrophage dysfunction in individuals with mild asthma. Am J Physiol Lung Cell Mol Physiol 2001, 280:L369-L375.

35. Varin A, Mukhopadhyay S, Herbein G, Gordon S: Alternative activation of macrophages by IL-4 impairs phagocytosis of pathogens but potentiates microbial-induced signalling and cytokine secretion. Blood 2010, 115:353-362

36. Chupp GL, Lee CG, Jarjour N, Shim YM, Holm CT, He S, Dziura JD, Reed J, Coyle AJ, Kiener P, Cullen M, Grandsaigne M, Dombret MC, Aubier M, Pretolani M, Elias JA: A chitinase-like protein in the lung and circulation of patients with severe asthma. N Engl J Med 2007, 357:2016-2027.

37. Ober C, Tan Z, Sun Y, Possick JD, Pan L, Nicolae R, Radford S, Parry RR, Heinzmann A, Deichmann KA, Lester LA, Gern JE, Lemanske RF, Nicolae DL, Elias JA, Chupp GL: Effect of variation in CHI3L1 on serum YKL-40 level, risk of asthma, and lung function. N Engl J Med 2008, 358:1682-1691.

38. Tang H, Fang Z, Sun Y, Li B, Shi Z, Chen J, Zhang T, Xiu Q: YKL-40 in asthmatic patients, and its correlations with exacerbation, eosinophils and immunoglobulin E. Eur Respir J 2010, 35:757-760.

39. Lee CG, Dela Cruz CS, Herzog E, Rosenberg SM, Ahangari F, Elias JA YKL-40, a chitinase-like protein at the intersection of inflammation and remodeling. Am J Respir Crit Care Med 2012, 185:692-694.

40. Gavala ML, Kelly EA, Esnault S, Kukreja S, Evans MD, Bertics PJ, Chupp GL, Jarjour NN: Segmental allergen challenge enhances chitinase activity and levels of CCL18 in mild atopic asthma. Clin Exp Allergy 2013, 43:187-197.

41. de Nadai $P$, Charbonnier AS, Chenivesse $C$, Senechal S, Fournier C, Gilet J, Vorng $H$, Chang $Y$, Gosset $P$, Wallaert B, Tonnel AB, Lassalle P, Tsicopoulos A: Involvement of CCL18 in allergic asthma. J Immunol 2006, 176:6286-6293.

42. Luzina IG, Highsmith K, Pochetuhen K, Nacu N, Rao JN, Atamas SP: PKCalpha mediates CCL18-stimulated collagen production in pulmonary fibroblasts. Am J Respir Cell Mol Biol 2006, 35:298-305. 
43. Lensmar C, Katchar K, Eklund A, Grunewald J, Wahlstrom J: Phenotypic analysis of alveolar macrophages and lymphocytes following allergen inhalation by atopic subjects with mild asthma. Respir Med 2006, 100:918-925.

44. Holt PG, Oliver J, Bilyk N, McMenamin C, McMenamin PG, Kraal G, Thepen T: Downregulation of the antigen presenting cell function(s) of pulmonary dendritic cells in vivo by resident alveolar macrophages. J Exp Med 1993, 177:397-407.

45. Nieuwenhuizen NE, Kirstein F, Jayakumar J, Emedi B, Hurdayal R, Horsnell WG, Lopata AL, Brombacher F: Allergic airway disease is unaffected by the absence of IL-4Ralpha-dependent alternatively activated macrophages. J Allergy Clin Immunol 2012, 130:743-750.

46. Ford AQ, Dasgupta P, Mikhailenko I, Smith EM, Noben-Trauth N, Keegan AD: Adoptive transfer of IL-4Ralpha + macrophages is sufficient to enhance eosinophilic inflammation in a mouse model of allergic lung inflammation. BMC Immunol 2012, 13:6.

47. Herbert C, Scott MM, Scruton KH, Keogh RP, Yuan KC, Hsu K, Siegle JS, Tedla N, Foster PS, Kumar RK: Alveolar macrophages stimulate enhanced cytokine production by pulmonary CD4+ T-lymphocytes in an exacerbation of murine chronic asthma. Am J Pathol 2010, 177:1657-1664.

48. Nagarkar DR, Bowman ER, Schneider D, Wang Q, Shim J, Zhao Y, Linn MJ, McHenry CL, Gosangi B, Bentley JK, Tsai WC, Sajjan US, Lukacs NW, Hershenson MB: Rhinovirus infection of allergen-sensitized and -challenged mice induces eotaxin release from functionally polarized macrophages. J Immunol 2010, 185:2525-2535.

49. Nassenstein C, Dawbarn D, Pollock K, Allen SJ, Erpenbeck VJ, Spies E, Krug N Braun A: Pulmonary distribution, regulation, and functional role of Trk receptors in a murine model of asthma. J Allergy Clin Immunol 2006, 118:597-605.

50. Atochina-Vasserman EN, Winkler C, Abramova H, Schaumann F, Krug N, Gow AJ, Beers MF, Hohlfeld JM: Segmental allergen challenge alters multimeric structure and function of surfactant protein $D$ in humans. Am J Respir Crit Care Med 2011, 183:856-864.

51. Erpenbeck VJ, Hohlfeld JM, Volkmann B, Hagenberg A, Geldmacher H, Braun A, Krug N: Segmental allergen challenge in patients with atopic asthma leads to increased IL-9 expression in bronchoalveolar lavage fluid lymphocytes. J Allergy Clin Immunol 2003, 111:1319-1327.

52. Knothe $S$, Mutschler V, Rochlitzer S, Winkler C, Ebensen T, Guzman CA, Hohlfeld J, Braun A, Muller M: The NKT cell ligand alphagalactosylceramide suppresses allergic airway inflammation by induction of a Th1 response. Vaccine 2011, 29:4249-4255.

53. Winkler AR, Nocka KH, Sulahian TH, Kobzik L, Williams CM: In vitro modeling of human alveolar macrophage smoke exposure: enhanced inflammation and impaired function. Exp Lung Res 2008, 34:599-629.

54. Livak KJ, Schmittgen TD: Analysis of relative gene expression data using real-time quantitative PCR and the 2(-Delta Delta $C(T))$ Method. Methods 2001, 25:402-408.

doi:10.1186/1471-2172-15-12

Cite this article as: Winkler et al:: Impact of endobronchial allergen provocation on macrophage phenotype in asthmatics. BMC Immunology 2014 15:12.

\section{Submit your next manuscript to BioMed Central and take full advantage of:}

- Convenient online submission

- Thorough peer review

- No space constraints or color figure charges

- Immediate publication on acceptance

- Inclusion in PubMed, CAS, Scopus and Google Scholar

- Research which is freely available for redistribution 